\title{
PENINGKATAN MANAJEMEN DATA MELALUI SISTEM APLIKASI POSYANDU DI KECAMATAN LOWOKWARU MALANG
}

\author{
Lailil Muflikhah $^{1 *}$, Daneswara Jauhari ${ }^{1}$, Indriati ${ }^{1}$ \\ ${ }^{1}$ Fakultas Ilmu Komputer, Universita Brawijaya, Malang, Indonesia \\ *Penulis Korespondensi:lailil@ub.ac.id
}

\begin{abstract}
Abstrak
Pos Pelayanan Terpadu (Posyandu) merupakan upaya dari masyarakat dalam meningkatkan kesehatan masyarakat dengan memberikan layanan kesehatan dasar secara mudah dan ekonomis.Namun kurangnya partisipasi dari masyarakat akan pentingnya Posyandu mendorong dilakukannya kegiatan pengabdian masyarakat ini dengan membuat sistem aplikasi berbasis android. Sistem ini ditujukan untuk pencatatan selama kegiatan posyandu dan pemberian informasi seputar kegiatan informasi serta perkembangan balita. Adapun tahapan kegiatan dimulai dengan surveykegiatan terkait dengan analisis kebutuhan sistem, perancangan dan implmementasi sistem, tahapan selanjutnya adalah pelatihan terhadap pemakai aplikasi, baik bagi kader posyandu maupun ibu balita. Tahap akhir merupakan evaluasi terhadap tingkat kegunaan sistem bagi petugas dan peserta posyandu. Berdasarkan hasil kuisioner diperoleh bahwasannnya sistem aplikasi tersebut telahmemenuhi kebutuhan untuk dioperasikan secara efektif (83.67\% responden), efisien (65\% responden) dengankemudahan (89.3\% responden) serta $79 \%$ menyatakan tingkat kepuasan yang relatif tinggi.
\end{abstract}

Kata kunci: android, kader, kesehatan, posyandu, sistem

\begin{abstract}
Integrated Service Post (Posyandu) is an effort of the community in improving public health by providing basic health services in effective and efficient. However, the lack of participant on the importanceof Posyandu encourages this community service to develop application system based on android. Thissystem is intended for reserving the data information including cadre of Posyandu and children under five. First, survey activities related to system requirements analysis, design and implementation of the system. The next stage is training on application users, eithercadre orchildren's parent. The final stage is usability evaluation of application system. Based on questionnaire, the evaluation result is effectively rate of $83.6 \%$, efficiently rate of $65 \%$, easily rate of $89.3 \%$, and satisfaction rate of $79.3 \%$.
\end{abstract}

Keywords: android, cadre, health, posyandu,system

\section{PENDAHULUAN}

Kecenderungan masyarakat yang seringkali mengabaikan pentingnya kesehatan, menyebabkan rendahnya upaya tindakan preventif akan suatu penyakit. Ditambah lagi, mahalnya upaya untuk pengobatan terhadap suatu penyakit mendorong terbentuknya kegiatan Pos pelayanan terpadu (Posyandu). Posyandu merupakan bentuk partisipasi masyarakat yang membawa arti sangat besar bagi kesehatan dan kesejahteraan masyarakat secara operasional. Posyandu adalah salah satu bentuk peran serta masyarakat dalam pembangunan kesehatan dengan sasaran utamanya adalah kelompok bayi, anak balita, ibu hamil, ibu meneteki serta wanita usia subur. Pelaksanaan kegiatan posyandu merupakan salah satu upaya untuk mendekatkan masyarakat terhadap jangkauan pelayanan kesehatan primer. Semakin tinggi pelayanan kesehatan terhadap masyarakat diharapkan akan semakin meningkat derajat kesehatan masyarakat (Depkes RI, 2000).Salah satu upaya deteksi dini gizi buruk terhadp balita melalui pelaksanaan kegiatan posyandu. (Bintanah, 2010). Sehingga upaya pemberian layanan prima petugas posyandu sangat diperlukan dalam pelaksanaan kegiatan dan peningkatan partisipasi masyarakat. Adanya korelasi antara pemberian bantuan opersional dengan peningkatan kinerja dari kader posyandu(Wirapuspita, 2013).

Posyandu merupakan salah satu dari program kerja (PokJa-4) di kegiatan Pembinaan Kesejahteraan Keluarga (PKK) dengan waktu pelaksanaan sebulan sekali di lingkungan RT 15/ RW 1 kelurahan Tunggul Wulung (Posyandu Kenanga) dan di lingkunan RW 6 kelurahan Tlogomas (Posyandu Mawar). Adapun salah satu sasarannya ditujukan kepada balita yang 
berusia $>0$ bulan sampai dengan $\leq 59$ bulan. Meskipun sudah terbentuk, peranan dari Posyandu tidak terlaksana secara optimal. Hal ini terlihat rendahnya tingkat partisipasi dari peserta posyandu (ibu balita) untuk datang ke tempat penyelenggara dengan maksimal sebesar $60 \%$. Seperti halnya peserta Posyandu yang diselenggarakan di RT 15 kelurahan Tunggul Wulung, jumlah yang hadir maksimal 20 balita dari total 32 peserta balita yang terdaftar. Sedangkan RW 6 kelurahan Tlogomas, rata-rata sekitar 70 dari 102 peserta.

Ada beberapa kendala dalam pelaksanaan kegiatan yang dirasa kurang efektif, yakni pemberitahuan, pendataan peserta yang keluar dan masuk, serta pencatatan (berat badan dan tinggi badan) yang kemudian dilakukan pencocokan terhadap grafik tumbuh kembang balita. Upaya pemberitahuan akan laksanakannya kegiatan posyandu di kedua tempat tersebut dilakukan melalui selebaran kertas undangan (di Tunggul Wulung) dan secara lesan dalam acara pengajian rutin mingguan (di Tlogomas). Sehingga kemungkinan terjadi ketidaktahuan pelaksanaan kegiatan, oleh karena informasinya tidak sampai ke orang tua peserta. Pada waktu pelaksanaan kegiatan, dilakukan pencatatan secara manual oleh petugas. Tidak adanya pengecekan secara otomatis terhadap peserta yang sudah lulus ( $>59$ bulan) dan pendataan bayi yang baru dilahirkan, sehingga tidak dapat mengetahui secara pasti keberadaan jumlah peserta saat itu. Juga selama kegiatan berlangung, terkadang petugas posyandu terkadang mengalami kesulitan dalam pencocokan terhadap grafik tumbuh kembang balita dikarenakan diperlukan ketrampilan pembacaan yang tepat dan telliti. Pada akhir kegiatan terjadi perekapan data dari buku peserta oleh petugas kesehatan yang hadir di setiap kegiatan tersebut.

Berdasarkan kasus di atas, maka penulis tertarik untuk membantu pelaksanaan kegiatan Posyandu sehingga bisa berjalan secara optimal melalui pembuatan suatu aplikasi sistem informasi posyandu yang terintegrasi dan berbasis mobile, dimana bisa diakses melalui handphone. Dengan aplikasi ini diharapkan bisa membantu pelaksanaan kegiatan Posyandu sehingga bisa berjalan secara optimal.

\section{Tinjuan Pustaka}

\subsection{Android}

Android pada awalnya dikembangkan oleh Android, Inc., dengan dukungan finansial dari Google, yang kemudian membelinya pada tahun 2005. Sistem operasi Android (OS) dibuat dengan dasar dari kernel Linux terbuka. Berbeda dengan OS iPhone, Android adalah open source, yang berarti pengembang dapat memodifikasi dan menyesuaikan OS untuk setiap telepon. Oleh karena itu, ponsel berbasis Android yang berbeda mungkin memiliki berbagai antarmuka pengguna grafis UI yang beragam meskipun mereka menggunakan OS yang sama. Ponsel Android biasanya datang dengan beberapa aplikasi bawaan dan juga mendukung program pihak ketiga. Pengembang dapat membuat program untuk Android menggunakan Software Developer Kit (SDK) Android gratis.. Pengembangan aplikasi dengan menggunakan Android ini dapat dilakukan dengan bahasa pemrograman Java. Saat ini pengembangan Android sudah mencapai versi 6.0 yang disebut Marshmallow.

\subsection{JavaScript Object Notation (JSON)}

JavaScript Object Notation (JSON) adalah format pertukaran data yang mudah dibaca dan ditulis oleh manusia, serta mudah diterjemahkan dan dibuat (generate) oleh komputer. Format ini dibuat berdasarkan bagian dari Bahasa Pemprograman JavaScript, Standar ECMA-262 Edisi ke-3 Desember 1999 (Json, 2015). JSON merupakan format teks yang tidak bergantung pada bahasa pemprograman apapun karena menggunakan gaya bahasa yang umum digunakan oleh programmer keluarga C termasuk C, C++, C\#, Java, JavaScript, Perl, Python dll.

\subsection{Representational State Transfer (REST)}

Representational State Transfer (REST) adalah suatu arsitektur metode komunikasi yang sering diterapkan dalam pengembangan layanan berbasis web (Eka, 2015). Arsitektur REST, yang umumnya dijalankan via HTTP (Hypertext Transfer Protocol), melibatkan proses pembacaan laman web tertentu yang memuat sebuah file XML atau JSON, File inilah yang menguraikan dan memuat konten yang hendak disajikan. Setelah melalui sebuah proses definisi tertentu, konsumen akan bisa mengakses antarmuka aplikasi yang dimaksudkan (Eka, 2015).

REST kerap dipergunakan dalam mobile application, situs web jejaring sosial, mashup tools, dan automated business processes. Arsitektur REST yang decoupled (terpisah) serta beban komunikasi yang ringan antara produsen dan konsumen membuatnya populer di dunia cloud-based API, seperti yang disajikan oleh Amazon, Microsoft, dan Google.

\subsubsection{REST API}

Layanan berbasis web yang menggunakan arsitektur REST semacam itu dinamakan RESTful APIs (Application Programming Interfaces) atau REST APIs (Eka, 2015). REST API banyak dibutuhkan, seiring populernya pengembangan aplikasi Smartphone khusus nya Android yang menggunakan data dari server.

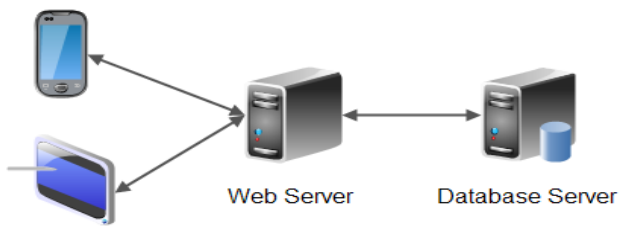

Gambar 1. Sistem REST-API 
Pada Gambar 1 mengenai gambaran sistem aplikasi mobile khususnya Android, tergambarkan bahwa Android dapat menggunakan fungsi-fungsi yang ada di Web Server, dan mungkin mengambil atau menyimpan data ke Database Server dengan adanya REST API.

\subsubsection{Web Service}

Web service adalah aplikasi sekumpulan data (database), perangkat lunak (software) atau bagian dari perangkat lunak yang dapat diakses secara remote oleh berbagai piranti dengan sebuah perantara tertentu (Pandwinata, 2013). Secara umum, web service dapat diidentifikasikan dengan menggunakan URL seperti hanya web pada umumnya (Pandwinata, 2013). Namun yang membedakan web service dengan web pada umumnya adalah interaksi yang diberikan oleh web service. Berbeda dengan URL web pada umumnya, URL web service hanya menggandung kumpulan informasi, perintah, konfigurasi atau sintaks yang berguna membangun sebuah fungsi-fungsi tertentu dari aplikasi.

\subsubsection{PHP}

PHP atau yang memiliki kepanjangan Hypertext Preprocessor, merupakan suatu bahasa pemrograman yang difungsikan untuk membangun suatu website dinamis PHP merupakan script untuk pemrograman script web server-side, script yang memuat dokumen HTML on the fly, dokumen HTML yang dihasilkan dari suatu aplikasi bukan dokumen HTML yang dibuat dengan menggunakan editor teks atau editor HTML (Pandwinata, 2013). Dengan menggunakan PHP maka maintenance suatu situs web menjadi lebih mudah. Proses update data dapat dilakukan dengan menggunakan aplikasi yang dibuat dengan menggunakan script PHP.

\subsection{Material Design}

Material Design adalah bahasa pemrograman visual yang dibuat oleh Google, Bahasa pemrogaman ini menggunakan tampilan visual yang menarik tapi sederhana (Nugroho, 2015). Material Design bukan menawarkan konsep perubahan secara masive, tetapi ini adalah langkah yang signifikan untuk menuju New Visually Representative language. Teknologi ini akan memicu design berbasis artificial yang diwujudkan kedalam bentuk yang nyata.

\section{METODE PELAKSANAAN}

Terdapat dua kegiatan utama dalam pelaksanaan pengabdian masyarakat ini, meliputi: pembuatan dan pelatihan penggunaan perangkat lunak. Adapun perangkat lunak yang dibangun digunakan sebagai pendukung pelaksanan kegiatan Posyandu setempat, baik bagi petugas maupun pesertanya.
Adapun metoda pelaksanaan kegiatan sebagaimana berikut:

a. Diskusi dengan petugas posyandu tentang kendala ataupun permasalahan yang dihadapi dari pelaksanaan posyandu

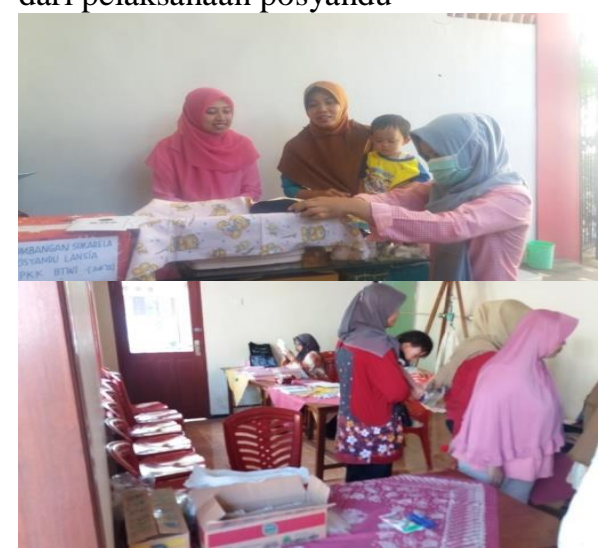

Gambar 2.Situasi dan diskusi selama pelaksanaan kegiatan posyandu

b. Diskusi permasalahan seputar pencatatan data balita (berat badan, tinggi badan, lingkar kepala) (sudah dilakukan)

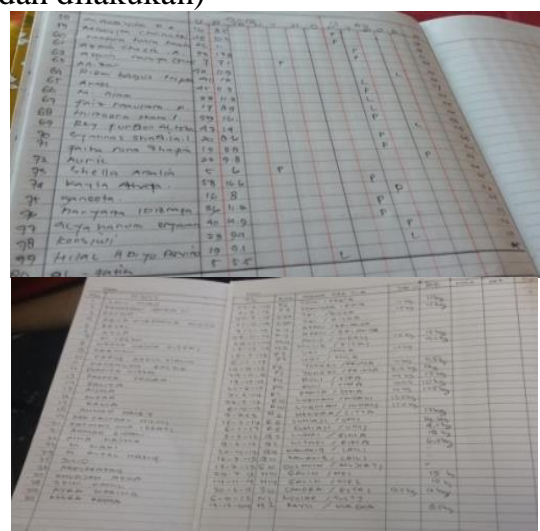

Gambar 3. Pencatatan data balita selama pelaksanaan kegiatan posyandu di kedua mitra
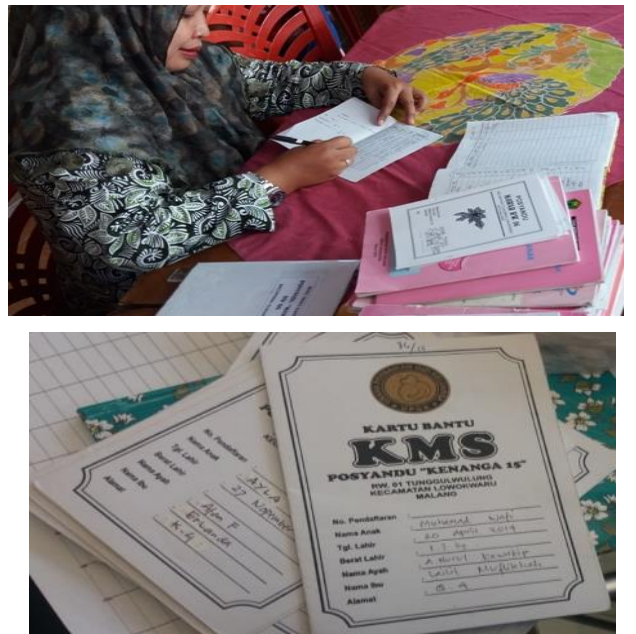

Gambar 4. Bukupesertaposyandu di keduamitra 


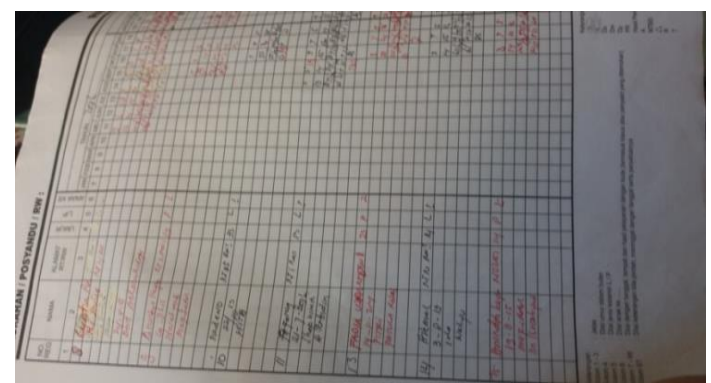

Gambar 5. Rekapitulasi data

balitapesertaposyanduolehpetugaspuskesmas c. Rancang bangun sistem aplikasi yang sesuai kebutuhan kader posyandu dan masyarakat terkait

\subsection{Perancangan dan pembuatan perangkat lunak}

Terdapat tiga model perancangan, mulai dari segi pengguna terhadap sistem sampai dengan ke ranah implementasi sistem secara fisik, yakni meliputi:

1. Use Case diagram

2. Entity Relation diagram

3. Class diagram

\subsubsection{Use Case Diagram}

Diagram ini merupakan rancangan program aplikasi dalam prospektif pengguna terhadap sistem yang melibatkan petugas dan admin yang secara interaktif dapat melakukan pengisian dan update data. Meski pada peserta umumnya bisa melihat tampilan baik secara tekstual atau numerik maupun grafis.

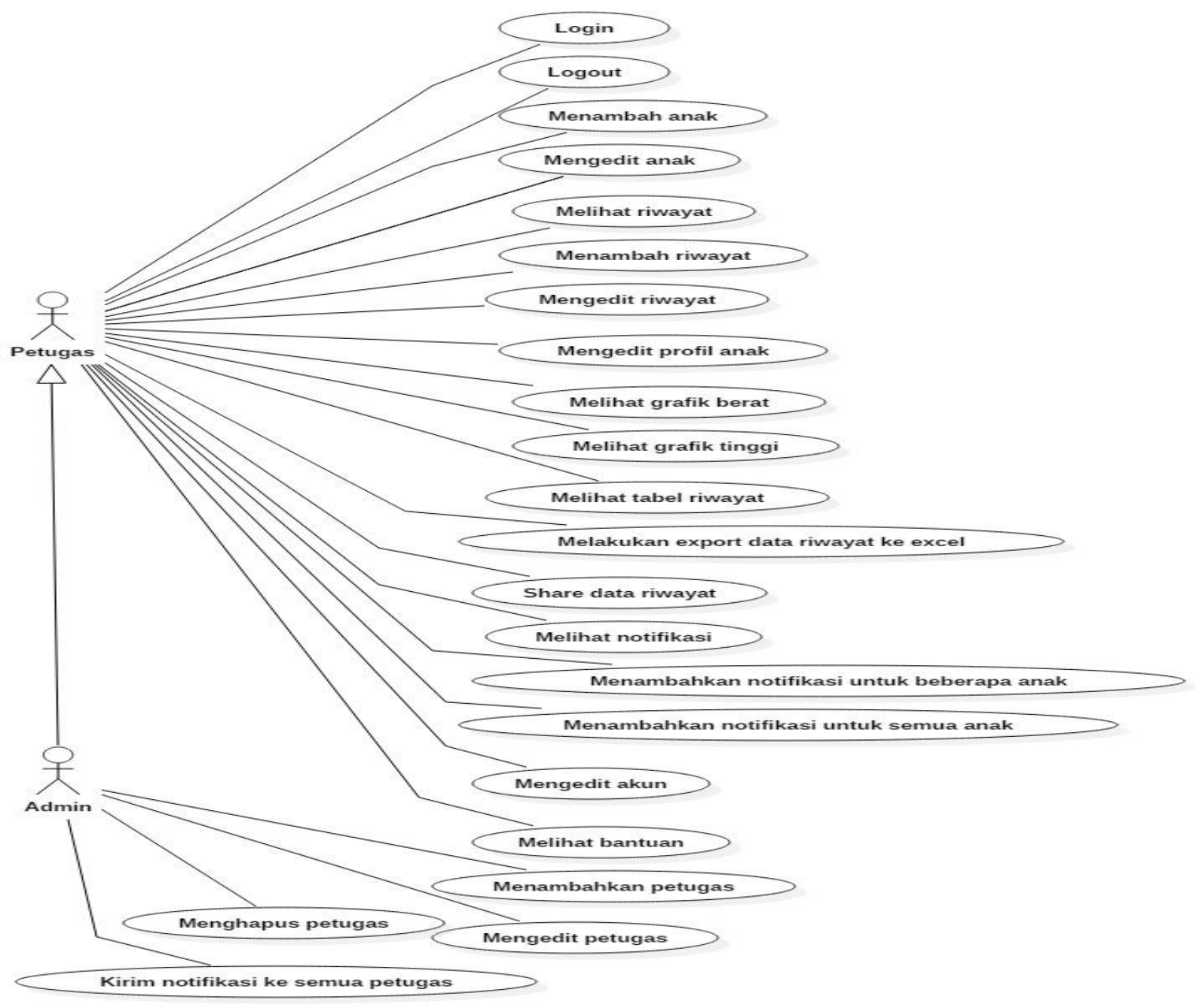

Gambar 6.Use Case diagram untuk program aplikasi Posyandu 


\subsubsection{Class Diagram}

Dalam perancangan berikutnya digunakan berbasis class (objek) sebagai platform pembuatan program aplikasi sehingga terbentuk setiap class akan menampilkan bentuk luaran seperti pengisian data peserta (tambahAnak), kirim notifikasi (petugas maupun peserta) sampai dengan tampilan berupa grafik.

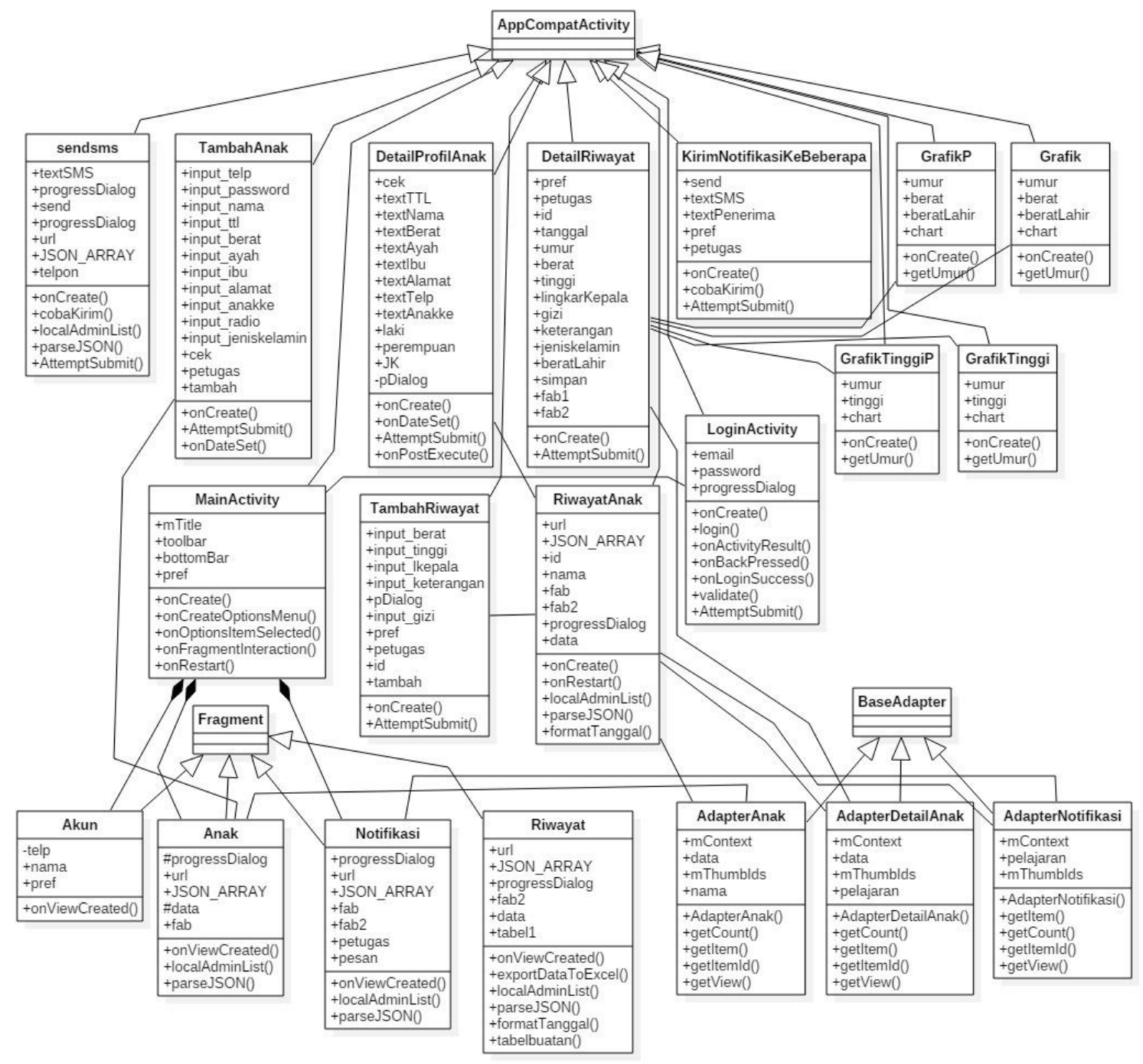

Gambar 7. Class Diagram Program Aplikasi Posyandu

\subsubsection{Entity Relationship Diagram (ER-Diagram)}

Perancangan penyimpanan data yang terintegrasi digambarkan dalam bentuk ER diagram. Beberapa data terkait pelaksanaan kegiatan posyandu, meliputi: data peserta (balita) dan data petugas dan beberapa informasi terkait kegiatan pelaksanaan/ penyuluhan. 


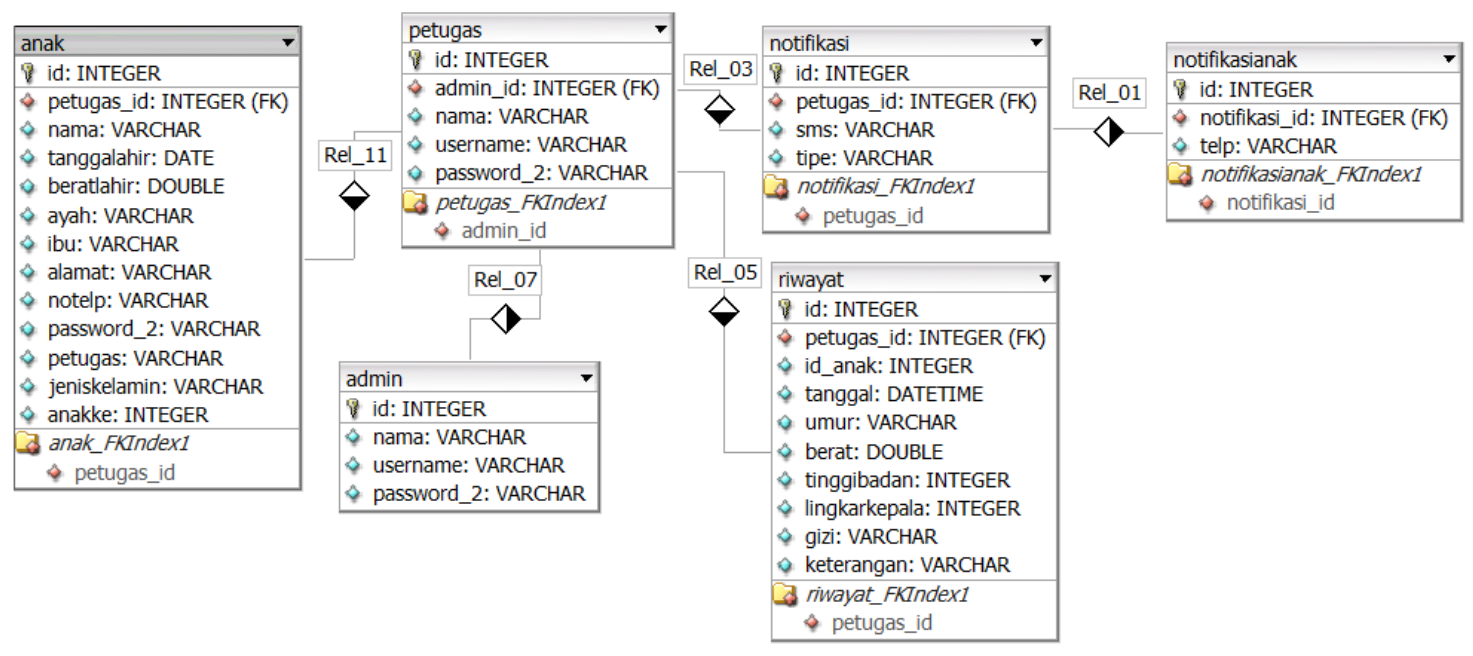

Gambar 8.Entity Relationship diagram program aplikasi posyandu

\section{IMPLEMENTASI HASIL}

Setelah tahap perancangan, maka dilakukan implementasi pembuatan program aplikasi dengan spesifikasi perangkat keras dan perangkat lunak yang digunakan implementasi program dengan spesifikasi berikut:

\section{A. SpesifikasiPerangkatKeras:}

- Laptop denganspesifikasiprocessor Intel(R) Core(TM) i3-3217U, RAM 8 GB, Harddisk $500 \mathrm{~GB}$

- HP Samsung Galaxy J5 Prime

\section{B. SpesifikasiPerangkatLunak :}

- Android Studio

- Genymotion

Sistem aplikasi yang dibuat dapat diimplementasikan melalui emulator sebagai memudahkan untuk proses debugging sebelum di plug-in di telepon selular yang berbasis android.

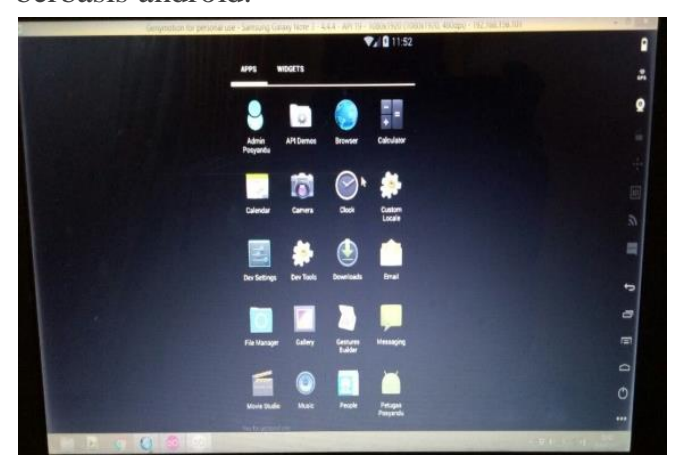

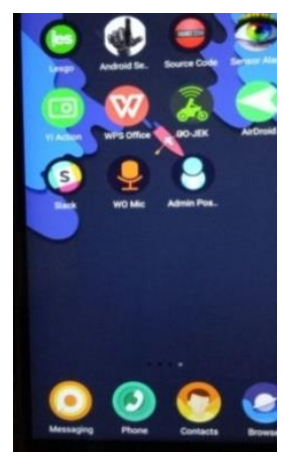

Gambar 9. Tampilan awal program aplikasi melalui emulator dan telepon selular

Selanjutnya, ditunjukkan beberapa contoh bentuk luaran yang ditampilkan dari program aplikasi ini, meliputi: Login, pengisian data, tampilan dalam bentuk grafik, share output maupun ekspor data dalam bentuk file excel serta pemberian notifikasi ke petugas posyandu.

1) Melakukan login kedalam aplikasi Admin Posyandu dengan cara mengisi form yang disediakan yaitu username dan password, setelah itu tekan tombol Login, jika berhasil maka akan tampil halaman Anak.

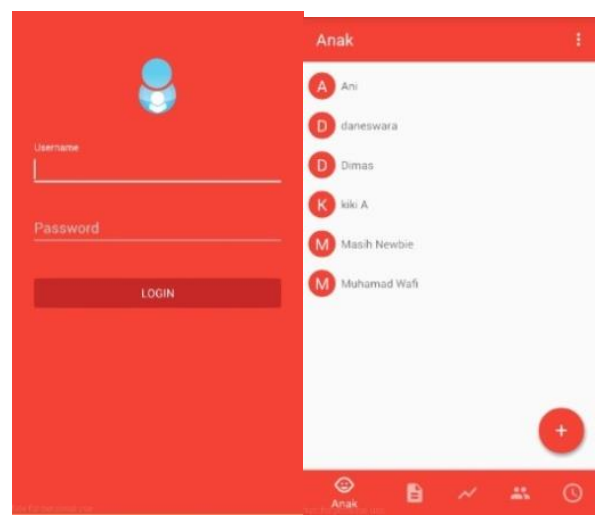

Gambar 10. Tampilan Menu Login 
1. Membuat akun anak dengan menekan tombol + pada pojok kanan bawah, dilanjutkan dengan mengisi biodata dari anak pada form pendaftaran yang tersedia, diakhiri dengan menekan tombol tambah.

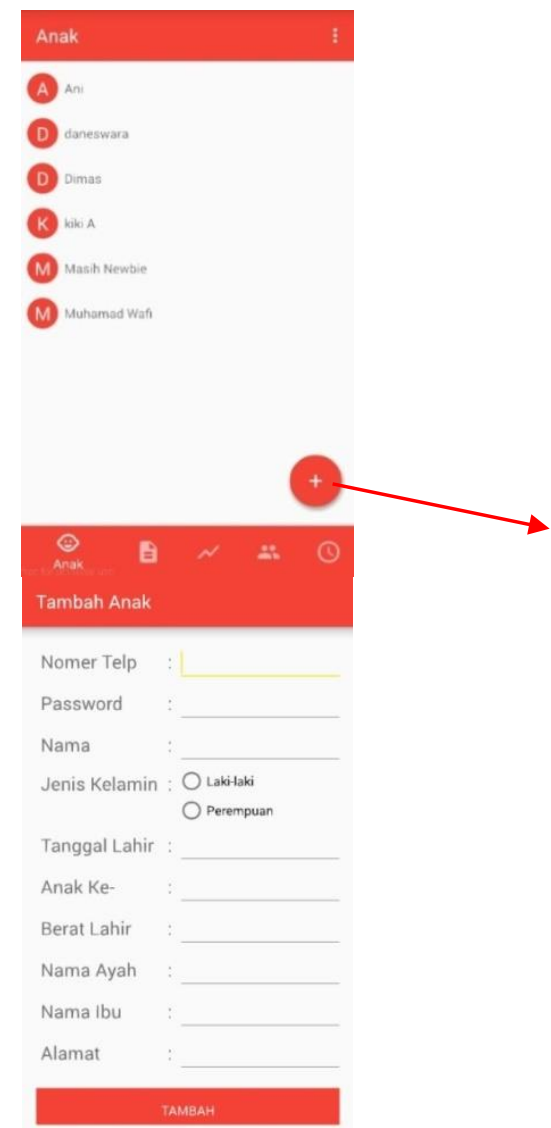

Gambar 11. Tampilan menu tambah peserta posyandu

2. Tampilan sebagai luaran dari aplikasi ini bisa juga berupa grafik sehingga lebih memudahkan pembacaan oleh peserta dan diberikan informasi secara otomatis jika terjadi penyimpangan (tidak terdapat kenaikan)
4. Membagikan informasi sampai dengan dapat dilakukan penyimpanan dalam bentuk excel sehingga memudahkan untuk dilakukan rekapitulasi oleh pihak petugas puskesmas.

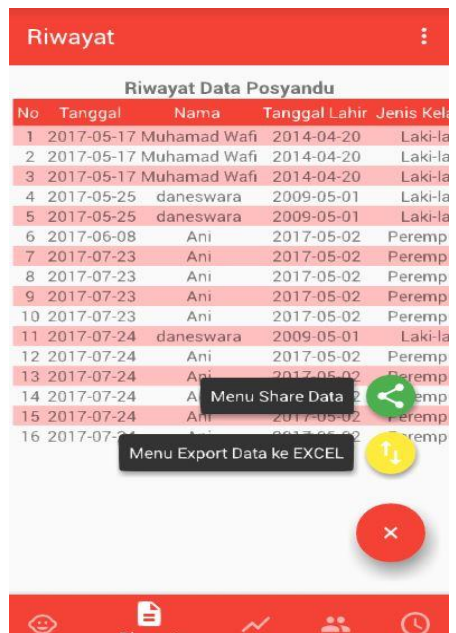

Gambar 13.Tampilan data rekapitulasi selama kegiatan

5. Notifikasi terkirim bisa dilihat pada menu notifikasi, didalam menu ini juga terdapat tiga jenis tipe pengiriman, yaitu pengiriman notifikasi sms kesemua anak, sms ke beberapa orang, dan wa ke beberapa orang.

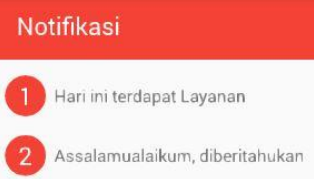

3.

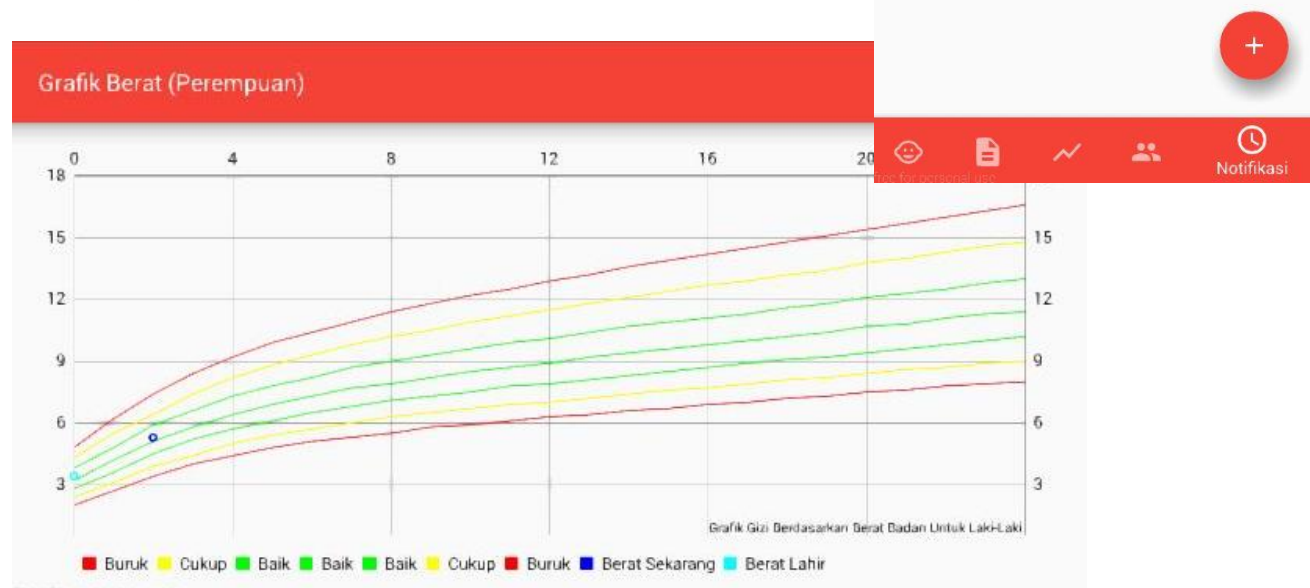

Gambar 12. Tampilan dalam bentuk grafik pencatatan berat badan peserta 


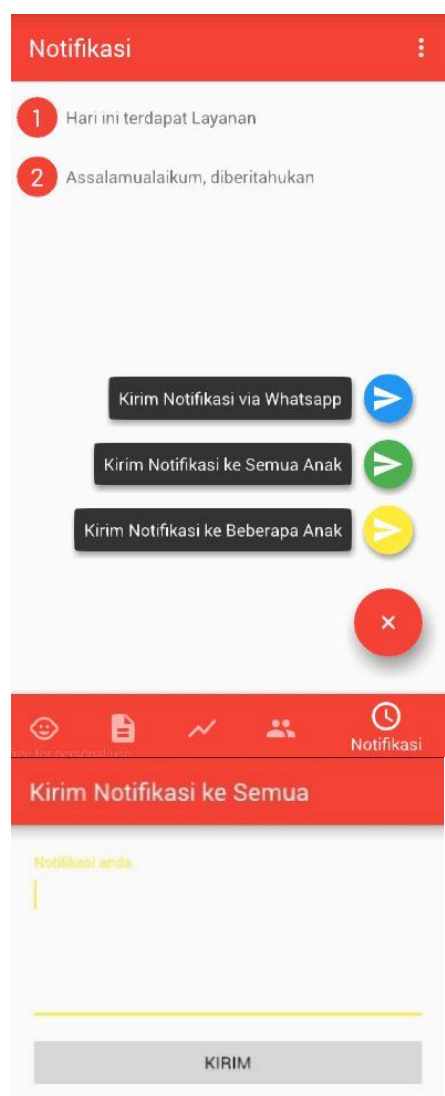

Gambar 14. Tampilan notifikasi ke peserta posyandu

\section{EVALUASI KEGIATAN}

Sebagai upaya untuk mengetahui keberhasilan program kegiatan pengabdian masyarakat ini, dilakukan sosialisasi melalui pemberian pelatihan kepada kader atau petugas dan peserta posyandu dengan pemberianhak akses yang berbeda.

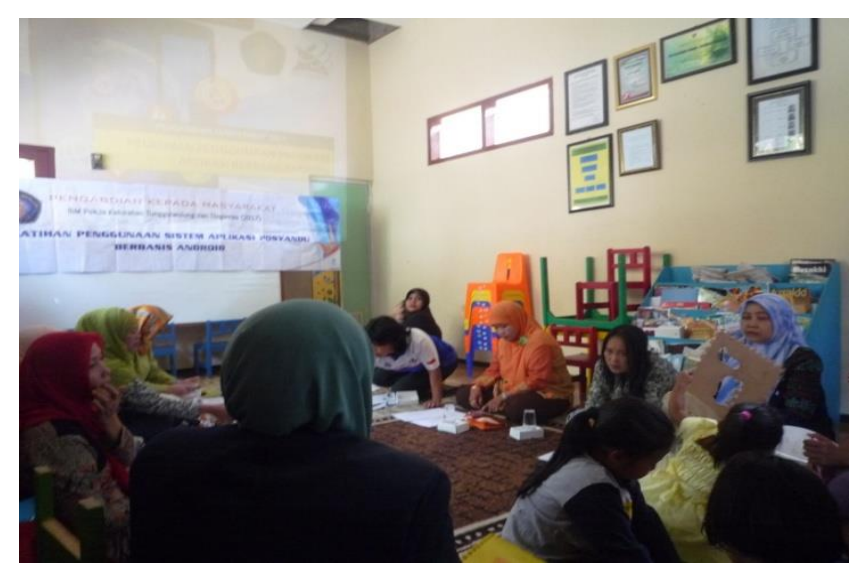

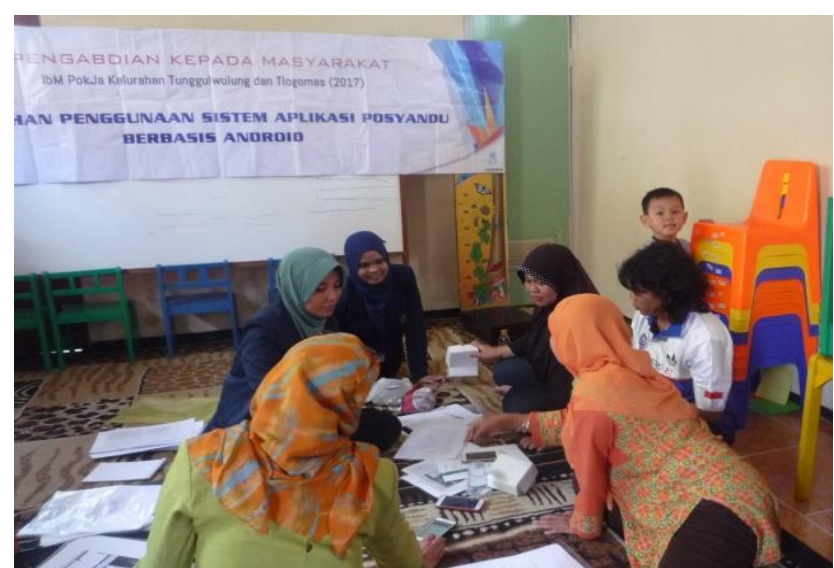

Gambar 15. Pelatihan penggunaan program aplikasi android oleh petugas dan peserta posyandu

Uji usabilitas dilakukan dengan pemberian kuisionerkepada peserta pelatihan sebagai upaya untuk mengetahui tingkat keefektifan, keefisiensian dan kemudahan serta tingkat kepuasan pengguna dari sistem aplikasi. Berdasarkan jawaban responden dihasilkan bahwasannya $83.67 \%$ efektif, $65 \%$ efisien, dan $89.3 \%$ mudah untuk digunakan serta $79.3 \%$ menyatakan tingkat kepuasan peserta dalam penggunaan aplikasi untuk mendukung kegiatan posyandu. Lebih lanjut mereka menyatakan bahwasannya aplikasi ini bisa terus berkelanjutan pengoperasiannya, hal ini ditunjukkan dengan kesediaan mereka untuk memelihara agar bisa tetap bisa diakses.

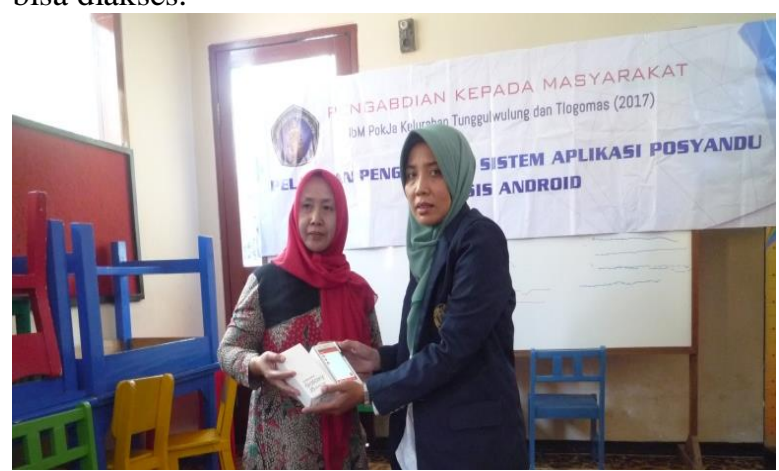

Gambar 16. Serah teima Telepon Selular (HP) sebagai media aplikasi program

\section{KESIMPULAN}

Telah dilakukan pelaksanaan pengabdian masyarakat dengan pembuatan sistem aplikasiberbasis android sebagai alat bantu pelaksanaan kegiatan posyandu di Kelurahan Tunggul Wulung (RT 15) dan Kelurahan Tlogomas (RW 6). Adapun fitur-fitur yang tersedia dalam sistem tersebut meliputi: input data, update data dan menampilkan data balita baik dalam bentuk tekstual maupun grafis, hingga notifikasi informasi seputar kegiatan posyandu. Sistem tersebut telah disosialisasikan ke pihak pengguna dengan pemberian pelatihan serta telpon selular ke kedua mitra sehingga dapat mengimplementasikan secara optimal. 


\section{UCAPAN TERIMA KASIH}

Pelaksanaan pengabdian kepada masyarakat ini didanai oleh Direktorat Penelitian dan Pengabdian Masyarakat, Direktorat Jenderal Penguatan Riset Dan Pengembangan, Kementerian Riset, Teknologi dan Pendidikan Tinggi dalam program hibah Iptek Bagi Masyarakat (IbM) tahun 2017.

\section{DAFTAR PUSTAKA}

Airin. (2010). PosyanduMerupakan Garda DepanKesehatanBalita.

Bintanah, S.(2010). Gambaran Kegiatan Posyandu Dalam Rangka Deteksi Dini Gizi Buruk Di Wilayah Kerja Puskesmas Halmahera. Prosiding Seminar Nasional Unimus (https://jurnal.unimus.ac.id) [ Diakses tanggal 30 Agustus 2017]

Bumi, Cindar. (2005). PengaruhIbu Yang BekerjaTerhadap Status GiziAnakBalita di KelurahanMangunjiwanKabupatenDemak,

BukuKesehatanIbudanAnak. CetakanBaru. Jakarta Dinkes Kota Medan. 2008. ProfilKesehatan Kota Medan Tahun 2008, Medan

Depdagri. (2001)

PedomanUmumRevitalisasiPosyanduNomor $411.3 / 1116 / \mathrm{SJ} / 2001$

Depkes RI.

ModulPelatihanRevitalisasiPosyandu, Jakarta

Eka. (2015). REST (REPRESENTATIONAL STATE TRANSFER) [online]. Tersedia di: $<$ http://ekajogja.com/definisi/restrepresentational-state-transfer/> [Diakses 01 Desember 2016]

http://www.rakyatmerdeka.co.id

http://digilib.unnes.ac.id

Json. (2015). Pengenalan JSON [online]. Tersedia di: <http://www.json.org/json-id.html> [Diakses 01 Desember 2016]

Nugroho, Dipto. (2015). ArtiSebenarnya Material Design [online]. Tersedia di: <http://diptonugroho.blogspot.co.id/2015/07/tu torial-mudah-membuat-material-design.html> [Diakses 01 Desember 2016]

Pandwinata, Vina. (2013). Pengertian Web Service [online]. Tersedia di:http://saptafina13.blogspot.co.id/2013/04/pe ngertian-web-service.html> [Diakses 01 Desember 2016]

Wirapuspita, R. (2013). Insentif dan Kinerja Kader Posyandu. Jurnal Kesehatan Masyarakat. 9 (1), 58-65. Universitas Negeri Semarang. 